\title{
Acute diabetes complications across transition from pediatric to adult care in Ontario and Newfoundland and Labrador: a population-based cohort study
}

\author{
Rayzel Shulman MD PhD, Longdi Fu MSc, John C. Knight PhD, Astrid Guttmann MDCM MSc, \\ Roger Chafe PhD
}

\section{Abstract}

Background: Transition to adult diabetes care is a high-risk period for acute complications, yet the optimal transition care model is unknown. To gain insight into the impact on health outcomes of system-level transition processes that reflect resourcing differences, we examined acute complications in youth with diabetes across transition in 2 Canadian provinces with different transition care models.

Methods: We used linked provincial health administrative data for Ontario and Newfoundland and Labrador to create 2 parallel cohorts of youth with diabetes diagnosed before age 15 years who turned 17 between 2006 and 2011. Participants were followed until 2015 (maximum age $21 \mathrm{yr}$ ). We described rates of and proportion of participants with at least 1 diabetes-related hospital admission at age 15-17 years and 18-20 years, standardized according to material deprivation based on the 2006 Canadian Marginalization Index. We compared diabetes-related admissions at age 15-17 years and 18-20 years in the Ontario cohort.

Results: The cohorts consisted of 2525 youth in Ontario and 93 in Newfoundland and Labrador. In Newfoundland and Labrador, 39 participants $(42.0 \%)$ were in the lowest socioeconomic quintile, versus $326(12.9 \%)$ in Ontario. The standardized rate of diabetesrelated hospital admissions per 100 person-years was 13.5 (95\% confidence interval [CI] 12.6-14.4) at age 15-17 years and 14.4 $(95 \% \mathrm{Cl} 13.5-15.3)$ at age $18-20$ years in Ontario, and $11.4(95 \% \mathrm{Cl} 7.0-15.8)$ at age $15-17$ years and $10.5(95 \% \mathrm{Cl} 6.4-14.6)$ at age 18-20 years in Newfoundland and Labrador. In Ontario, there was no association between the rate (adjusted rate ratio 1.10, $95 \% \mathrm{Cl} 0.94-1.28$ ) or occurrence (adjusted odds ratio $1.03,95 \% \mathrm{Cl} 0.91-1.17$ ) of diabetes-related admissions across transition.

Interpretation: Although posttransition care is delivered differently in the 2 provinces, rates of adverse events across transition were stable in both. Coordinated support during transition is needed to help mitigate adverse events for young adults in both provinces. Delivery of other health care and social services, including primary care, may be influencing the risk of adverse events after transition to adult care.

Y oung adults with type 1 diabetes face particular challenges related to having a chronic illness that requires intensive daily self-management and regular medical follow-up during a period when their social, developmental, educational and living situations are often in flux. ${ }^{1}$ During this vulnerable period, youth are at increased risk for acute life-threatening complications, such as diabetic ketoacidosis, and for poor glycemic control, which both confer an increased risk of serious chronic complications. ${ }^{2-6}$ In a population-based Ontario cohort, the rate of diabetes-related hospital admissions increased significantly, from 7.6 to 9.5 per 100 patient-years, in the 2 years after transfer to adult care ${ }^{4}$ This is also a time when young adults become disconnected from diabetes care. Over a third of youth in a US study had a care gap of more than 6 months when transferring from pediatric to adult care, ${ }^{7}$ and we found that almost half $(47.0 \%)$ of
Ontario youth had a gap of more than 12 months in diabetes care across their transition to adult care. ${ }^{8}$

We do not know the best way to structure processes of transition to adult care, ${ }^{9-11}$ especially in areas with few physician or other specialized diabetes resources. Little is known about the impact on health outcomes of system-level transition processes that reflect these resourcing differences. In some jurisdictions, shortages of specialists mean that not all patients can be cared for by endocrinologists.

\section{Competing interests: None declared.}

This article has been peer reviewed.

Correspondence to: Rayzel Shulman, rayzel.shulman@sickkids.ca CMAJ Open 2020. DOI:10.9778/cmajo.20190019 
Because of variations in how different provinces organize transition care, a comparison of outcomes across provinces may indicate whether jurisdictions that rely on a generalist model of care have outcomes comparable to those of jurisdictions with a more organized network of pediatric diabetes care and transition to predominantly specialist-led adult care. In this study, we examined the occurrence of acute diabetes complications across the transition period in 2 Canadian provinces, Ontario and Newfoundland and Labrador, both of which have some of the highest reported rates of diabetes globally ${ }^{12,13}$ but different structures for transition and posttransition care.

\section{Methods}

We conducted an observational population-based study of 2 parallel cohorts of youth with diabetes 3 years before and after age 18 years in Ontario and Newfoundland and Labrador using health administrative databases.

\section{Diabetes care in Ontario and Newfoundland and Labrador}

There are several important differences in the structure and delivery of diabetes transition care in Ontario and Newfoundland and Labrador that led us to select these 2 provinces. Children with diabetes in Ontario, the largest province in Canada, receive medical care at one of 35 specialized pediatric diabetes centres ( 5 tertiary and 30 community) coordinated by the Ontario Paediatric Diabetes Network. Each centre has a multidisciplinary team consisting of physicians, nurses, dietitians and social workers. ${ }^{14}$ Centres staffed by pediatric physicians (general pediatricians or pediatric endocrinologists) need to transfer care to adult care providers by age $18 .^{8,14} \mathrm{In}$ 2015, $28(80 \%)$ of the 35 centres referred at least some patients to an adult endocrinologist, and there was a wide range of clinic-specific transition practices. ${ }^{15}$

Newfoundland and Labrador is a smaller province and has a single tertiary care pediatric diabetes centre that cares for over half of all children with diabetes in that province. The majority of adolescents with type 1 diabetes followed in St. John's are referred to a young adult clinic in St. John's that is run by a nurse practitioner and overseen by an internist. There are no standard protocols for transfer of care for patients living outside of St. John's.

In both provinces, residents have universal government insurance that covers all medically necessary health care services. At the time of this study, there was no universal government insurance for prescription drugs for youth in either province. Drug costs are paid out-of-pocket, through private extended health benefits, or by the Ontario Drug Benefit Program or the Newfoundland and Labrador Prescription Drug Program (which cover families who receive social assistance). Public funding is available for insulin pumps for people with type 1 diabetes who meet eligibility criteria related to diabetes management in both provinces, although, at the time of this study, Newfoundland and Labrador had some restrictions on coverage after age $25 .{ }^{16}$

\section{Data sources}

In Ontario, the following data sets were linked by means of unique encoded identifiers and analyzed at ICES: the Pediatric Ontario Diabetes Database (a registry of all Ontario residents aged $<19$ yr with a diagnosis of diabetes based on a validated algorithm that uses 4 diabetes-related physician billing claims over 2 years [ $83 \%$ sensitivity, $99 \%$ specificity]), ${ }^{17}$ Hospital Discharge Abstract Database (information on discharges from acute care facilities), Ontario Health Insurance Plan database (physician billing claims), National Ambulatory Care Reporting System (information on emergency department visits), Registered Persons Database (demographic characteristics and vital statistics including outmigration of all legal residents in Ontario), Ontario Registrar General - Death (for cause of death) and 2006 Canadian census to assign neighbourhood material deprivation quintiles based on the 2006 Canadian Marginalization Index. ${ }^{18}$

In Newfoundland and Labrador, the cohort was identified through a provincial diabetes database kept at the Janeway Pediatric Research Unit, St. John's. This database captures all patients in the province diagnosed with type 1 diabetes between 1987 and 2015, based on the reporting of all diabetes nurses and diabetes educators across the province. Case definition and ascertainment are described elsewhere. ${ }^{13,19}$ Patient records were linked via coded identifiers to the following provincial administrative databases: the Provincial Discharge Abstract Database (discharges from acute care facilities), beneficiary registry database (demographic characteristics), physician claims database, Provincial Mortality System (mortality and cause of death) and 2006 Canadian census to assign neighbourhood material deprivation quintiles based on the 2006 Canadian Marginalization Index. ${ }^{18}$

To comply with privacy legislations, cell sizes less than 6 are reported as such.

\section{Study population and setting}

For both provinces, we included youth residing in their respective province who were diagnosed with diabetes before age 15 years, had a valid provincial health insurance number and turned 17 between Nov. 1, 2006, and Mar. 31, 2011. We followed patients until Mar. 31, 2015 to a maximum age of 21 years. Although we were unable to distinguish between diabetes types in Ontario, we have previously shown that nearly all (94.8\%) children in Ontario with diabetes have type $1 . .^{14,20}$ The Newfoundland and Labrador cohort included only patients diagnosed with type 1 diabetes. In Ontario, we excluded youth ineligible for provincial health insurance from age 15 to 19 and those who died before their 19th birthday. We also excluded people in Ontario with no diabetes-related physician visits from age 15 to 16 because they may have moved out of the province or were receiving care from providers who do not bill the provincial health plan. Furthermore, it would be highly unlikely for a person with type 1 diabetes to have no diabetes-related physician visits at this age. We did not apply this exclusion to the Newfoundland and Labrador cohort because the physician claims database does not include 
visits to non-fee-for-service physicians, who account for about $35 \%$ of physicians in that province.

\section{Outcomes}

We ascertained outcomes including death, all-cause hospital admissions, diabetes-related admissions and admissions for diabetic ketoacidosis from age 15 to 20 . We translated diagnostic codes for diabetes-related preventable hospital admissions, using the Agency for Healthcare Research and Quality specifications, to the enhanced Canadian version of the International Classification of Diseases and Related Health Problems, 10th Revision codes to identify admissions related to diabetic ketoacidosis and diabetes. ${ }^{21,22}$

\section{Baseline characteristics}

We measured socioeconomic status using the material deprivation index from the 2006 Canadian Marginalization Index. ${ }^{18}$ We categorized geographic residence as urban if the patient's postal code was located in a census metropolitan area and as rural otherwise.

\section{Statistical analysis}

Provincial privacy legislation does not allow sharing of individual patient data across provinces, so we could not combine the data sets for the 2 provinces. Therefore, we analyzed the cohorts separately. We described the baseline characteristics of patients with diabetes on their 17 th birthday in either province. For both provinces, we described the rates and occurrence of at least 1 event of all admissions, admissions related to diabetes (including diabetic ketoacidosis) and admissions related to diabetic ketoacidosis in 2 mutually exclusive age categories (15-17 yr and 18-20 yr), standardized according to material deprivation.

Owing to the small sample in Newfoundland and Labrador, we had insufficient power to make precise estimates or between-group comparisons for rare outcomes such as diabetes-related admissions and diabetic ketoacidosis. In the Ontario cohort only, we compared the rate of and proportion of youth with any diabetes-related admission before and after age 18 using a Poisson and a logistic regression model, respectively. In both models, we controlled for baseline characteristics including sex, material deprivation and duration of diabetes.

\section{Ethics approval}

We obtained research ethics board approval from The Hospital for Sick Children and the Newfoundland and Labrador Health Research Ethics Authority.

\section{Results}

Figure 1 shows the number of participants included in the 2 cohorts after the exclusion criteria were applied. The final cohorts consisted of 2525 youth in Ontario and 93 in Newfoundland and Labrador. The Ontario cohort contributed 7579.8 person-years to the follow-up period of age 15-17 years and 7549.7 person-years to the follow-up period of age 18-20 years. The corresponding values for the Newfoundland and Labrador cohort were 279 and 278.8. Table 1 shows the baseline characteristics of the 2 cohorts. In Newfoundland and

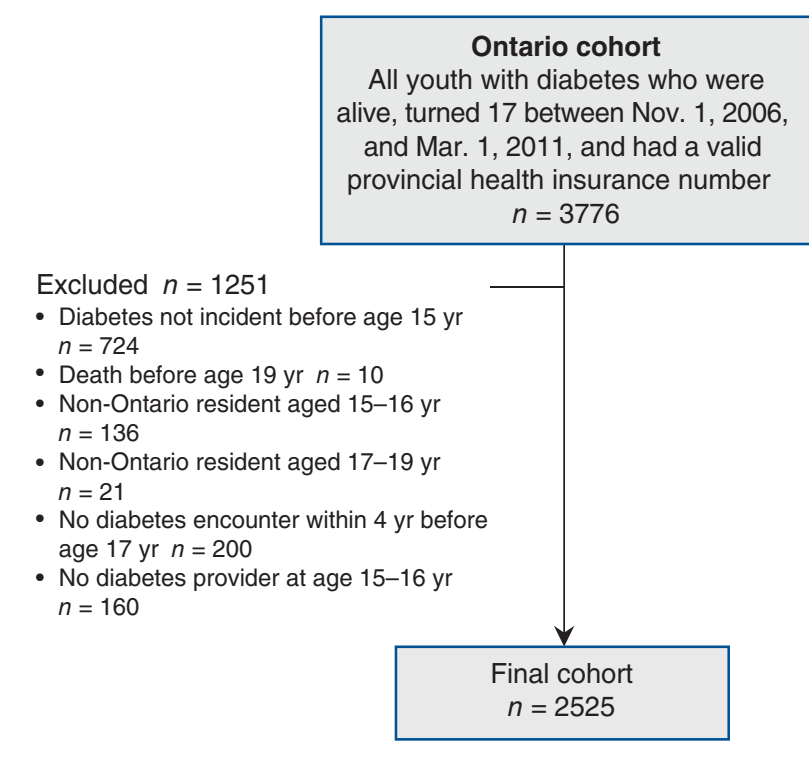

\section{Ontario cohort}

All youth with diabetes who were and Mar. 1, 2011, and had a valid $n=3776$
Figure 1: Flow diagram showing participant selection.

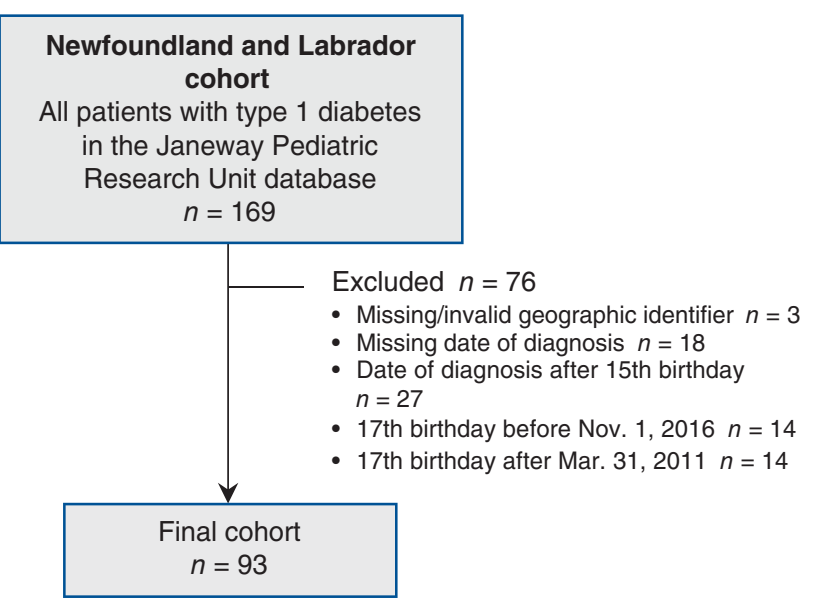

r 


\begin{tabular}{|c|c|c|}
\hline \multicolumn{3}{|c|}{$\begin{array}{l}\text { Table 1: Baseline characteristics of youth with diabetes in } \\
\text { Ontario and Newfoundland and Labrador on their 17th } \\
\text { birthday }\end{array}$} \\
\hline \multirow[b]{2}{*}{ Characteristic } & \multicolumn{2}{|c|}{ No. (\%) of participants* } \\
\hline & $\begin{array}{l}\text { Ontario } \\
n=2525\end{array}$ & $\begin{array}{l}\text { Newfoundland } \\
\text { and Labrador } \\
\quad n=93\end{array}$ \\
\hline Male sex & $1309(51.8)$ & $47(50.5)$ \\
\hline \multicolumn{3}{|l|}{ Duration of diabetes, yr } \\
\hline Mean \pm SD & $7.4 \pm 3.8$ & $7.9 \pm 3.8$ \\
\hline Median (IQR) & $6.7(4.3-10.2)$ & $7.6(4.5-11.0)$ \\
\hline \multicolumn{3}{|l|}{ Deprivation quintile† } \\
\hline 1 (least deprived) & $702(27.8)$ & $13(14.0)$ \\
\hline 2 & 587 (23.2) & $13(14.0)$ \\
\hline 3 & $504(20.0)$ & $15(16.1)$ \\
\hline 4 & $364(14.4)$ & $13(14.0)$ \\
\hline 5 (most deprived) & $326(12.9)$ & 39 (41.9) \\
\hline Missing & $42(1.7)$ & $<6 \ddagger$ \\
\hline \multicolumn{3}{|l|}{ Rurality } \\
\hline $\begin{array}{l}\text { Not census metropolitan } \\
\text { area (rural) }\end{array}$ & $387(15.3)$ & $59(63.4)$ \\
\hline $\begin{array}{l}\text { Census metropolitan } \\
\text { area (urban) }\end{array}$ & $2138(84.7)$ & $34(36.6)$ \\
\hline \multicolumn{3}{|c|}{$\begin{array}{l}\text { Note: } I Q R=\text { interquartile range, } S D=\text { standard deviation. } \\
{ }^{*} \text { Except where noted otherwise. } \\
\text { †Based on the } 2006 \text { Canadian Marginalization Index. }{ }^{18} \\
\ddagger \text { Added to quintile } 5 \text { owing to small cell size. }\end{array}$} \\
\hline
\end{tabular}

Labrador, 39 participants (41.9\%) were in the most materially deprived quintile, versus $326(12.9 \%)$ in Ontario. A total of 59 participants $(63.4 \%)$ lived in a rural area in Newfoundland and Labrador, versus 387 (15.3\%) in Ontario.
Table 2 shows the rates of and proportion of participants with at least 1 all-cause hospital admission, diabetes-related admission or diabetic-ketoacidosis-related admission in each age category, standardized according to material deprivation, in the 2 provinces. The standardized rate of diabetes-related hospital admission per 100 person-years was 13.5 at age 15-17 and 14.4 at age 18-20 in Ontario, and 11.4 at age 15-17 and 10.5 at age 18-20 in Newfoundland and Labrador. In the Ontario cohort, there was no association between the rate of diabetes-related admissions (adjusted rate ratio $1.10,95 \%$ confidence interval $0.94-1.28$ ) or the proportion of participants with any diabetes-related admission (adjusted odds ratio $1.03,95 \%$ confidence interval $0.91-1.17$ ) at age $15-17$ and $18-20$.

\section{Interpretation}

In this population-based cross-provincial study, we describe the standardized rates of adverse events for 2 cohorts of youth with diabetes during the transition to adult care in 2 Canadian provinces with high rates of type 1 diabetes and different models of transition and posttransition care. We were not able to make any interprovincial comparisons owing to the small sample in Newfoundland and Labrador. However, we found that, in Ontario, there were no significant differences in the rate of or proportion of participants with any diabetesrelated hospital admission before and after the 18th birthday. Although we did not have enough power to compare outcomes in Newfoundland and Labrador before and after the 18th birthday, the standardized rates of diabetes-related hospital admissions did not appear to be much different.

The rates of diabetes-related admissions that we report are higher than those reported in a previous populationbased study using Ontario administrative data from 1996 to 2002, 7.6-9.5 per 100 patient-years in the 2 years after transition to adult care. ${ }^{4}$ This suggests that more coordinated

\begin{tabular}{|c|c|c|c|c|}
\hline \multirow[b]{2}{*}{ Variable } & \multicolumn{2}{|c|}{ Ontario; age, yr } & \multicolumn{2}{|c|}{ Newfoundland and Labrador; age, yr } \\
\hline & $15-17$ & $18-20$ & $15-17$ & $18-20$ \\
\hline \multicolumn{5}{|l|}{ All admissions } \\
\hline Events/100 person-years $(95 \% \mathrm{Cl})$ & $23.8(22.6-25.0)$ & $25.4(24.1-26.6)$ & $20.9(15.0-26.8)$ & $22.6(16.5-28.7)$ \\
\hline Rate, \% $(95 \% \mathrm{Cl})$ & $32.7(30.8-34.7)$ & $34.0(32.1-36.0)$ & $32.0(21.7-42.3)$ & $31.8(21.5-42.1)$ \\
\hline \multicolumn{5}{|l|}{ Diabetes-related admissions } \\
\hline Events/100 person-years $(95 \% \mathrm{Cl})$ & $13.5(12.6-14.4)$ & $14.4(13.5-15.3)$ & $11.4(7.0-15.8)$ & $10.5(6.4-14.6)$ \\
\hline Rate, \% $(95 \% \mathrm{Cl})$ & $19.0(17.3-20.6)$ & $18.8(17.2-20.4)$ & $23.0(13.7-32.3)$ & $19.4(10.7-28.1)$ \\
\hline \multicolumn{5}{|l|}{$\begin{array}{l}\text { Diabetic-ketoacidosis-related } \\
\text { admissions }\end{array}$} \\
\hline Events/100 person-years $(95 \% \mathrm{Cl})$ & $10.6(9.8-11.4)$ & $12.7(11.8-13.6)$ & $7.7(4.0-11.4)$ & $8.8(5.1-12.6)$ \\
\hline Rate, \% $(95 \% \mathrm{Cl})$ & $14.9(13.4-16.4)$ & $17.7(16.1-19.3)$ & $17.3(8.8-25.9)$ & $18.9(10.2-27.5)$ \\
\hline
\end{tabular}


support during transition is needed to help mitigate adverse events for young adults with diabetes in both provinces.

We found that $41.9 \%$ of participants in the Newfoundland and Labrador cohort were in the most materially deprived quintile, versus $12.9 \%$ in Ontario, and that $63.4 \%$ of participants in Newfoundland and Labrador lived in a rural area, versus $15.3 \%$ in Ontario. There is a known association between both lower socioeconomic status and rural residence and an increased risk of diabetic ketoacidosis. ${ }^{23-26}$

Factors such as the delivery of health care services or other social services may mitigate the occurrence of adverse events, especially for those of low socioeconomic status and those living in rural areas in Newfoundland and Labrador. Furthermore, in Newfoundland and Labrador, there is less specialized adult type 1 diabetes care; however, primary care may be more consistent, which would also mitigate the occurrence of adverse events. This is supported by our findings that discontinuous primary care during transition is associated with an increased risk of adverse events in early adulthood for youth with diabetes and mental illness. ${ }^{8,27}$ We are currently doing further research in Newfoundland and Labrador to attempt to identify factors that may explain these comparable outcomes across the 2 provinces.

Our inability to combine provincial data sets and the relatively small sample from Newfoundland and Labrador illustrate some of the challenges of conducting multijurisdictional studies. Although we were able to report only standardized rates for hospital admissions, our results highlight the differences in diabetes care delivery between Ontario and Newfoundland and Labrador and provide insight into the challenge of organizing and evaluating diabetes transition care in different contexts. Our work to standardize the measurement of transition outcomes across these 2 provinces can serve as a model for future research and measurement of quality indicators. Furthermore, efforts are underway in Canada to create an environment that would enable greater cross-provincial data sharing and analysis. ${ }^{28}$

\section{Limitations}

Our study has several limitations. We cannot specifically attribute any observed differences in outcomes to the many differences in demographic composition and care delivery between provinces. We assume that most patients transfer to adult care at age 18 years; however, the transfer date for individual patients was unavailable. We also did not have information about glycemic control, a factor known to be associated with the risk of acute diabetes complications. Despite comparable data sources and consistent definitions to measure baseline characteristics and outcomes in both provinces, there may be differences in coding practices between the provinces. Also, we may have underascertained outcomes if participants moved out of province during the study.

We may have underestimated the rate of adverse events among those aged 18-20 years in Ontario since we excluded people with no diabetes-related physician visits from age 15 to 16 because they previously had moved out of the province, were receiving diabetes care from providers who did not bill the provincial health plan or, less likely, were not accessing care during that time. We did not apply this exclusion to the Newfoundland and Labrador cohort because the physician claims database does not include visits to non-fee-for-service physicians, who account for about $35 \%$ of physicians in Newfoundland and Labrador.

There was no study done to confirm the data quality or validity of the provincial diabetes database kept at the Janeway Pediatric Research Unit. It is possible that there are differences in other important outcomes between provinces, such as rates of clinic attendance and patient satisfaction, that we did not measure.

\section{Conclusion}

It is reassuring that we did not find large differences in the occurrence of acute diabetes complications across the age of transition to adult care within Ontario and Newfoundland and Labrador or within age categories between the provinces despite important interprovincial differences in access to specialized adult diabetes care. Although the standardized rates of adverse outcomes appear to be similar in the 2 provinces, it is possible that there are different mitigating factors influencing outcomes in either province; this should be further explored. This cross-provincial comparison study highlights 2 systemlevel transition processes that reflect resourcing differences between provinces and provides insight into the impact of these differences on health outcomes.

\section{References}

1. Peters A, Laffel L; American Diabetes Association Transitions Working Group. Diabetes care for emerging adults: recommendations for transition from pediatric to adult diabetes care systems: a position statement of the American Diabetes Association, with representation by the American College of Osteopathic Family Physicians, the American Academy of Pediatrics, the American Association of Clinical Endocrinologists, the American Osteopathic Association, the Centers for Disease Control and Prevention, Children with Diabetes, The Endocrine Society, the International Society for Pediatric and Adolescent Diabetes, Juvenile Diabetes Research Foundation International, the National Diabetes Education Program, and the Pediatric Endocrine Society (formerly Lawson Wilkins Pediatric Endocrine Society). Diabetes Care 2011;34: 2477-85.

2. Garvey KC, Wolpert HA, Rhodes ET, et al. Health care transition in patients with type 1 diabetes: young adult experiences and relationship to glycemic control. Diabetes Care 2012;35:1716-22.

3. Lyons SK, Becker DJ, Helgeson VS. Transfer from pediatric to adult health care: effects on diabetes outcomes. Pediatr Diabetes 2014;15:10-7.

4. Nakhla M, Daneman D, To T, et al. Transition to adult care for youths with diabetes mellitus: findings from a Universal Health Care System. Pediatrics 2009; 124:e1134-41.

5. Nathan DM, Bayless M, Cleary P, et al.; DCCT/EDIC Research Group. Diabetes control and complications trial/epidemiology of diabetes interventions and complications study at 30 years: advances and contributions. Diabetes 2013;62:3976-86.

6. Kapellen TM, Müther S, Schwandt A, et al. DPV initiative and the Competence Network Diabetes Mellitus funded by the German Federal Ministry of Education and Research. Transition to adult diabetes care in Germany - high risk for acute complications and declining metabolic control during the transition phase. Pediatr Diabetes 2018;19:1094-9.

7. Garvey KC, Markowitz JT, Laffel LM. Transition to adult care for youth with type 1 diabetes. Curr Diab Rep 2012;12:533-41.

8. Shulman R, Shah BR, Fu L, et al. Diabetes transition care and adverse events: a population-based cohort study in Ontario, Canada. Diabet Med 2018;35:1515-22.

9. Wafa S, Nakhla M. Improving the transition from pediatric to adult diabetes healthcare: a literature review. Can 7 Diabetes 2015;39:520-8.

10. Campbell F, Biggs K, Aldiss SK, et al. Transition of care for adolescents from paediatric services to adult health services. Cochrane Database Syst Rev 2016;(4): CD009794.

11. Crowley R, Wolfe I, Lock K, et al. Improving the transition between paediatric and adult healthcare: a systematic review. Arch Dis Child 2011;96:548-53. 
12. DIAMOND Project Group. Incidence and trends of childhood type 1 diabetes worldwide 1990-1999. Diabet Med 2006;23:857-66.

13. Newhook LA, Penney S, Fiander J, et al. Recent incidence of type 1 diabetes mellitus in children 0-14 years in Newfoundland and Labrador, Canada climbs to over 45/100,000: a retrospective time trend study. BMC Res Notes 2012;5:628.

14. Shulman R, Miller FA, Stukel TA, et al. Resources and population served: a description of the Ontario Paediatric Diabetes Network. CMA7 Open 2016;4: E141-6.

15. Shulman R, Chafe R, Guttmann A. Transition to adult diabetes care: a description of practice in the Ontario Paediatric Diabetes Network. Can 7 Diabetes 2019;43:283-9.

16. Insulin pump and supplies policy and administration manual. Toronto: Assistive Devices Program, Ministry of Health \& Long-Term Care; 2016. Available: www.health.gov.on.ca/en/pro/programs/adp/policies_procedures_manuals/docs/ insulin_pump_manual.pdf (accessed 2019 Feb. 1).

17. Guttmann A, Nakhla M, Henderson M, et al. Validation of a health administrative data algorithm for assessing the epidemiology of diabetes in Canadian children. Pediatr Diabetes 2010;11:122-8.

18. Matheson FI, Dunn JR, Smith KL, et al. Development of the Canadian Marginalization Index: a new tool for the study of inequality. Can 7 Public Health 2012;103(Suppl 2):S12-6.

19. Newhook LA, Curtis J, Hagerty D, et al. High incidence of childhood type 1 diabetes in the Avalon Peninsula, Newfoundland, Canada. Diabetes Care 2004; 27:885-8.

20. Amed S, Dean HJ, Panagiotopoulos C, et al. Type 2 diabetes, medicationinduced diabetes, and monogenic diabetes in Canadian children: a prospective national surveillance study. Diabetes Care 2010;33:786-91.

21. Shulman R, Stukel TA, Miller FA, et al. Low socioeconomic status is associated with adverse events in children and teens on insulin pumps under a universal access program: a population-based cohort study. BM7 Open Diabetes Res Care 2016;4: 000239

22. Diabetes short-term complications admission rate technical specifications. Prevention Quality Indicators \#1, technical specifications. Rockville (MD): Agency for Healthcare Research and Quality; 2012. Available: www.qualityindicators.ahrg.gov/ Downloads/Modules/PQI/V44/TechSpecs/PQI\%2001\%20Diabetes\%20Short -term\%20Complications\%20Admissions\%20Rate.pdf (accessed 2019 Feb. 1).

23. Shulman R, Luo J, Shah BR. Mental health visits and low socio-economic status in adolescence are associated with complications of type 1 diabetes in early adulthood: a population-based cohort study. Diabet Med 2018;35:920-8.

24. Berhan YT, Eliasson M, Möllsten A, et al.; Swedish Childhood Diabetes Study Group 2013. Impact of parental socioeconomic status on excess mortality in a population-based cohort of subjects with childhood-onset type 1 diabetes. Diabetes Care 2015;38:827-32.

25. Cengiz E, Xing D, Wong JC, et al.; T1D Exchange Clinic Network. Severe hypoglycemia and diabetic ketoacidosis among youth with type 1 diabetes in the T1D Exchange clinic registry. Pediatr Diabetes 2013;14:447-54.

26. Ampt A, van Gemert T, Craig ME, et al. Using population data to understand the epidemiology and risk factors for diabetic ketoacidosis in Australian children with type 1 diabetes. Pediatr Diabetes 2019;20:901-8.

27. Toulany A, Stukel TA, Kurdyak P, et al. Association of primary care continuity with outcomes following transition to adult care for adolescents with severe mental illness. FAMA Netw Open 2019;2:e198415.
28. Smith M, Schull M, McGrail K, et al. Pan-Canadian Real-World Health Data Network: building a national data platform. Int 7 Popul Data Sci 2018;3. doi https://doi.org/10.23889/ijpds.v3i4.984.

Affiliations: Department of Pediatrics (Shulman, Guttmann), The Hospital for Sick Children, University of Toronto; ICES (Shulman, Fu, Guttmann); Institute for Health Policy, Management and Evaluation (Shulman, Guttmann), University of Toronto, Toronto, Ont.; Faculty of Medicine (Knight, Chafe), Memorial University of Newfoundland, St. John's, Nfld.

Contributors: Rayzel Shulman contributed to the study conception and design, and to data analysis and interpretation, and drafted the manuscript. Astrid Guttmann and Roger Chafe were the senior authors and contributed equally to the work. They contributed to the study conception and design, and oversaw data analysis and interpretation. Longdi Fu and John Knight contributed to data analysis and interpretation. All of the authors revised the manuscript critically for important intellectual content, approved the final version to be published and agreed to be accountable for all aspects of the work.

Funding: This work was supported by Operating Grant SQS-145186, Pan-Canadian SPOR Network in Primary \& Integrated Health Care Innovations - Quick Strikes from the Canadian Institutes for Health Research and by the Janeway Children's Health Foundation. Astrid Guttmann received internal funding from The Hospital for Sick Children Research Institute.

Disclaimer: This study was supported by ICES, which is funded by an annual grant from the Ontario Ministry of Health and Long-Term Care (MOHLTC). The opinions, results and conclusions reported in this paper are those of the authors and are independent from the funding sources. No endorsement by ICES or the Ontario MOHLTC is intended or should be inferred. Parts of this material are based on data or information compiled and provided by the Canadian Institute for Health Information (CIHI) and the Newfoundland and Labrador Centre for Health Information (NLCHI). However, the analyses, conclusions, opinions and statements expressed in the material are those of the authors and not necessarily those of CIHI or NLCHI. Parts of this report are based on Ontario Registrar General information on deaths, the original source of which is ServiceOntario. The views expressed therein are those of the authors and do not necessarily reflect those of the Ontario Registrar General or the Ministry of Government Services.

Supplemental information: For reviewer comments and the original submission of this manuscript, please see www.cmajopen.ca/content/8/1/ E69/suppl/DC1. 